\title{
Milpirri
}

\section{Jennifer Biddle in discussion with Tracks Dance Company}

TIM NEWTH

TRACKS DANCE COMPANY

DAVID MCMICKEN

TRACKS DANCE COMPANY

AND

JENNIFER BIDDLE

UNIVERSITY OF NEW SOUTH WALES

-EDITORS' INTRODUCTION

This interview with Tim Newth and David McMicken, artistic directors of Tracks Dance Company (http://tracksdance.com.au) was conducted to complement Wanta Steve Jampijinpa Patrick's keynote presentation at Same but Different 2012, 'PulyaRanyi: Winds of Change' (see Patrick, this volume). Tim and David are the coproducers of Milpirri, the avant-garde Warlpiri ceremony that has become a biennale event since 2005.

\section{ISSN 1837-8692}

Cultural Studies Review 2015. @ 2015 Tim Newth, David McMicken and Jennifer Biddle. This is an Open Access article distributed under the terms of the Creative Commons Attribution 4.0 Unported (CC BY 4.0) License (https://creativecommons.org/licenses/by/4.0/), allowing third parties to copy and redistribute the material in any medium or format and to remix, transform, and build upon the material for any purpose, even commercially, provided the original work is properly cited and states its license. 
Milpirri is one of the most successful community arts collaborations today, modelling new trajectories for the arts industry and professional partnership. It is also one of the industry's least known initiatives (at least, to the broader, non-Warlpiri, public) because it remains radically site-specific. Lajamanu is the northern-most Warlpiri community (technically situated on traditional Gurindji country) of approximately five hundred people, located in the Tanami Desert, 950 kilometres south of Darwin. For one night only, every two years, Milpirri brings the whole Lajamanu community together in a spectacular high theatrical performance in Lajamanu itself. In this sense, Milpirri challenges the teleological narrative that drives the Australian nation state's deeply assumed position of sovereign centrality; the latent expectation that Indigenous societies embrace modernity ('Close the Gap') by leaving their homelands to gainfully 'participate' in the nation. Milpirri commandeers a participatory encounter on country, in place, with community. It ensures the enlivening and participatory 'inclusive' engagement of country, people and place in the very place from which it derives and to which it remains beholden. This constitutes a vital politics in an era when the 'remote' is increasingly figured as disadvantageous, as well as unhealthy, for sustainable and productive lives to take shape.

Milpirri began in 2005, although it is based upon a twenty-seven-year relationship between Tracks Dance Company and Lajamanu community that began in 1988; a relationship as Tim and David portray it, as personal as it is professional. It exemplifies how long-term relationships are vital to creative, collaborative heritage-making. As Jampiinipa (this volume) explains, Milpirri is a 'two way' bilingual, bicultural event, designed to bring Yapa (Warlpiri, Aboriginal people, human beings) and Kardiya (non-Warlpiri, non-Aboriginal people) together to enliven tradition for an intercultural twenty-first-century future. Milpirri is not just a metaphor. Younger Warlpiri are learning Jukurrpa (Dreaming) and their own obligatory relationships to country and community, in both Warlpiri and English, through the distinctive capacities of Milpirri to materialise new objects, memory and heritage, from graphics (banners, wristbands, t-shirts, DVDs) to school-based teaching of hip hop and traditional Yawalyu and Purlapa ceremonies that activate Ancestral activities, transformed and rejuvenated in the present. 


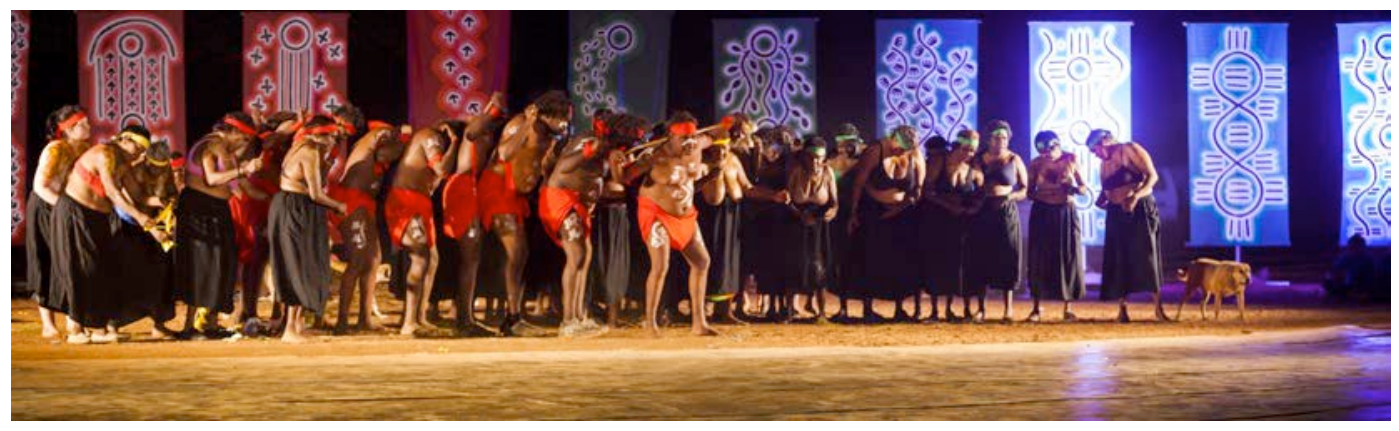

Image 1: Dancers, Milpirri Festival 2012, Lajamanu, NT (photograph: P. Eve; image (C) Tracks Dance Company 2012)

For the successful production of Milpirri, a commitment to continued community engagement is essential. High-level resourcing is also essential. To procure funding in the relentless three-to-five-years-in-advance cycles of competitive arts funding, as Tim and David discuss, no small strategic finesse is required, especially since Milpirri does not readily fit into any category of arts-based funding. Many dilemmas arise. How to make the case that traditional dance is contemporary? How to state that Lajamanu not New York (as Tim and David put it) is where leading aesthetic innovation is taking shape today? How to argue for something that is ultimately ephemeral? How to show that Milpirri isn't simply a portable, durable art form nor a tour-able event and that it, like the traditional Warlpiri forms of art and ceremony it relies upon, requires participatory repetition and iterative performance, to teach, to engage, to activate knowledge, country and heritage, by an entire remote community from school age to the elderly?

The newly released documentary Milpirri: Winds of Change, a co-production between PAW Media and People Pictures, screened on NITV on 30 October 2014, the same night that the sixth Milpirri-Milpirri (Jardi-Warnpa)-was performed in Lajamanu, Northern Territory (see http://www.pawmedia.com.au/news/milpirridocumentary-completed-107 and http://tracksdance.com.au/milpirri-jarda-warnpa for further information). 


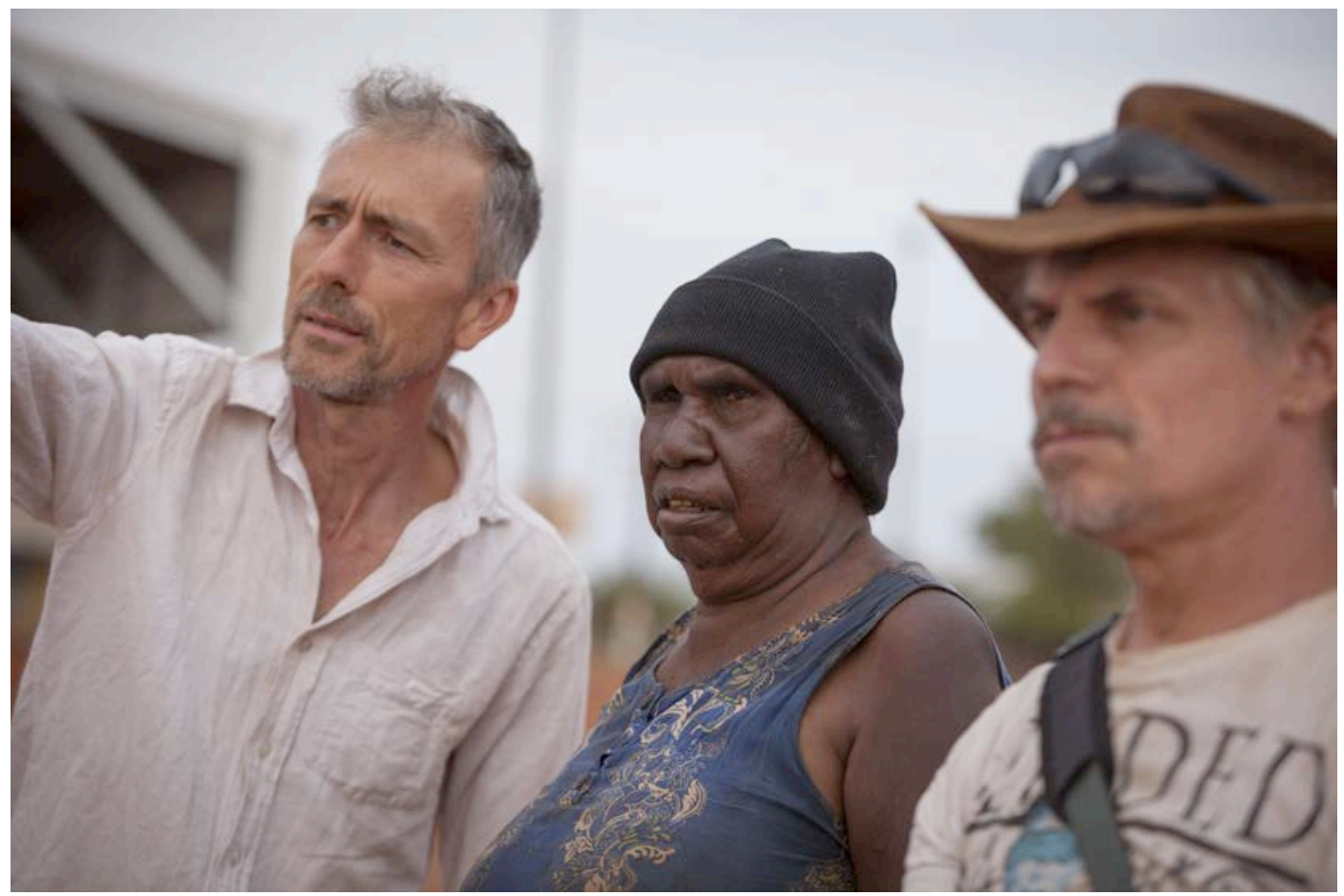

Image 2: Tim (Jampijinpa) Newth, Myra Nungarrayi Patrick, David (Japaljarri) McMicken, Milpirri Festival 2012, Lajamanu, NT (photograph: P. Eve; image @ Tracks Dance Company 2012)

Jennifer Biddle: We are here to talk a little bit about this experimental and innovative, biannual Warlpiri festival, or ceremony, that has been running since 2005, called Milpirri, which Tracks Dance Company has been involved in producing with Wanta Steve Jampijinpa Patrick. So I might just start out by asking, given that Milpirri is, in fact, a ceremonial performance based largely around dance, what you see as unique about Milpirri as an event, and what you see about dance as central to it?

David McMicken: One of the unique things about Milpirri is the huge amount of participation rates in it, that in a community of under five hundred people, that we can end up with over two hundred people performing in a show ... and the reason that they are attracted to doing that, I think, is because it speaks. It comes from structures that they understand ... Steve provides us with ceremony that we are not repeating, but ... the underlying reason for this ceremony and the structures in this ceremony and the learning within that, is what we start from, and so instantly the participants have an understanding that's not a Western English-based 
understanding. So the connection to the performers and the material is much stronger than you often find in Western arts practice.

Tim Newth: And also, I guess, the Milpirri performance was really built on fifteen years of working in that community. It's like no other project in that fifteen years. I remember we have done projects and we might be there three months and, you know, we'd be really happy with it, and there'd be participation in it, but ... it might be fifteen people who came in contact with it, that had actively been involved from the start to the end, and then it was gone, you know? It was, kind of, not talked about much afterwards. It kind of sat on the surface, if you like, and I guess as David is talking about Milpirri, it taps into the whole history of Warlpiri culture ... and so to actually take that fifteen years of understanding-which was both ways, Warlpiri people working with the white artists that work within Tracks and vice versa. And then link it in ... the result of that was this sense of belonging to Warlpiri people.

Jennifer: And a greater cultural and community based sense of that. Where did that idea of Milpirri, and that word come from originally?

Tim: There was a little bit of discussion early on, once we kind of had this idea of creating this performance event. At that point in time Steve was working in the [Lajamanu] school and Tracks's main link into the community had been through the school, and so there was this disjoint, you know. The older people didn't really understand why they would send their kids to school, what they were learning and what that was about, and the white staff really had no idea about Warlpiri cultural life that might be taught in ceremony, and how that all works. So it was about kind of linking those two things together.

David: I guess, really, it was a bit of a search, 'Has this worked in other places? Are there some things that we can kind of learn from other places?' And of course Garma $^{1}$ is something that has been successful. I think that started off some sort of exploration in Steve's mind, to go, 'Is there anything that sits in Warlpiri culture that might have a similar kind of ...'

Tim: ... or in his own even more personal, not just Warlpiri culture, but in his own...

David: ... he had to look into his own Jukurrpa ... and through that was self-esteem. The first time going back to his own country ${ }^{2} \ldots$ That ... sparking a really intense 
interest in Steve going, 'how does my son learn about this if I don't know what it is? How do we pass on real knowledge that connects us and make us survive on this land, if no one's teaching me?' And then, so he had to look at it himself, and say, 'Why aren't I learning this? Why do the old people think the young aren't ready? Why do the young think it's not worth learning?' So these questions were really strong in Steve, who had been working as a youth worker and as an educator, and had to answer that in himself, first. ${ }^{3}$ Having worked with us over a number of projects, he also saw that there was something in the way we worked that might assist him in answering that question. And it was about the two worlds living at the same time in the one space, rather than being seen, as most people do, as two completely separate worlds that are attacking each other ... it was about a Blackfella and a Whitefella conversation ... a respect for each other's culture, and an ability to be able to question as well understand. And it was the first time when Steve started initiating - all the other projects before that, really, had been driven by us ... and what we wanted to get out of it.

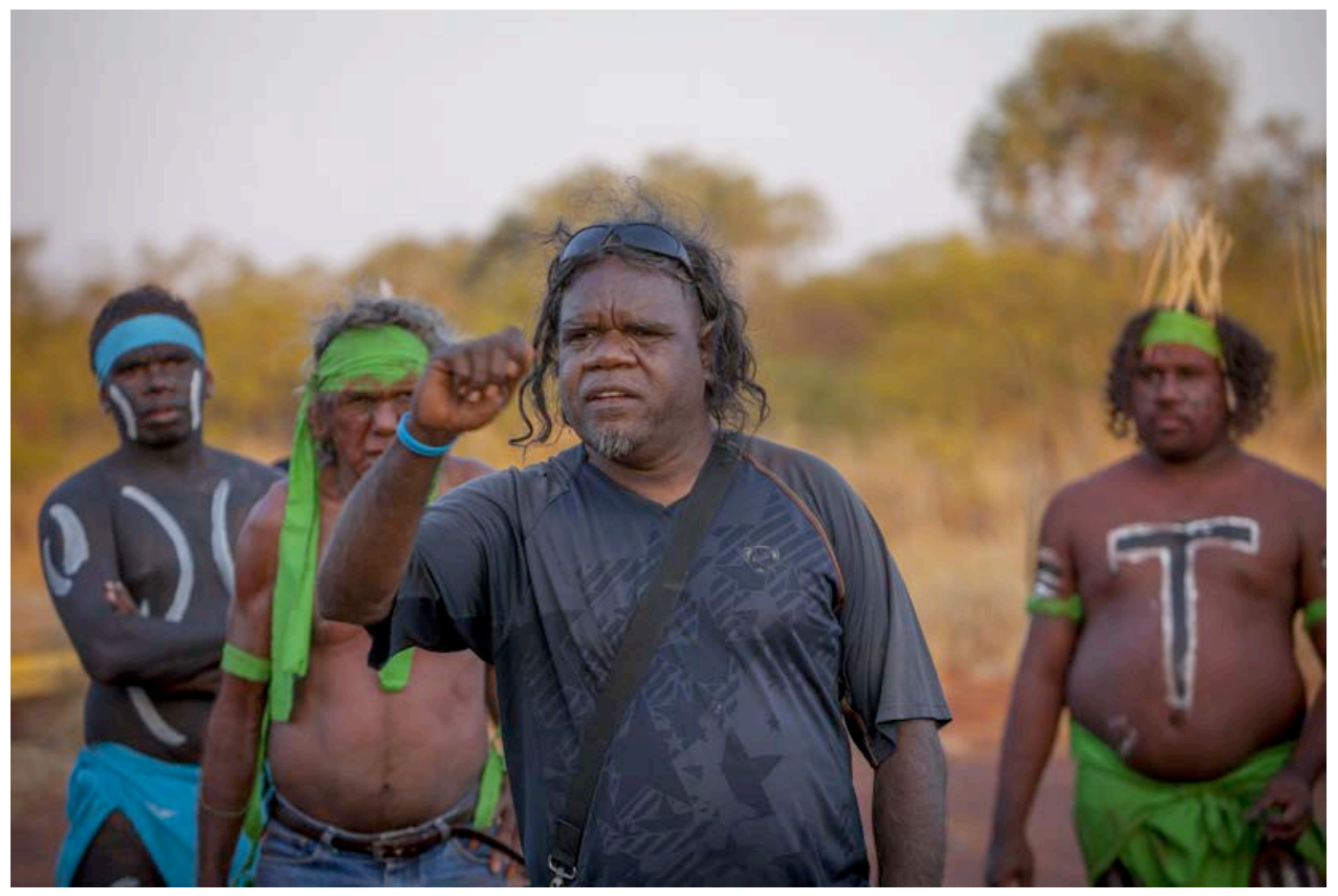

Image 3: Wanta Steve Jampijinpa Patrick, Milpirri Festival 2012, Lajamanu, NT (photograph: P. Eve; image (C) Tracks Dance Company 2012) 
Tim: I have a really clear image of seeing him on the back veranda with him going, 'I've got this kind of idea and I've been watching what you guys do, and I think, the two of them kind of match.'

David: And him searching for that metaphor where he went into the rainstorm Dreaming and going, ' $\mathrm{Ok}$, that Milpirri, that big thunderhead cloud, is the opposites working together.' And so once he got that ... he expanded that fairly quickly. At first it was just two opposites. It was like a Western education-Warlpiri education model. And then very quickly it became the thunder and lightning is the struggle, and then it became the green grass afterwards, once it had rained, and that is what we should be heading for, and so the metaphor very quickly unpackaged itself, probably by the time from that conversation through to the first Milpirri.

Jennifer: Let's talk about the experimentation that was those four colours? A little bit about it, because that is a really radical ... I mean, I think it is really important because kinship is proving to be a really useful way for explaining to outsiders about Warlpiri culture ... so ... the colours and the armband. Maybe just say what they are so people know?

Tim: Well Steve just put in ceremonial groupings, certain kinship groupings...

Jennifer: We call them moieties in anthropology.

Tim: So he basically chose four strong colours just to be able to represent each group ... and now they often talk about these groups in colour groupings ... but they know it is a shorthand in saying the blue group that it is Jampijinpa and Nampijinpa and Jangala and Nangala, instead of every time saying these names, it belongs to all of them, they can go, 'That blue group.' So it is shorthand but it also means people can understand very quickly where their place is physically. ${ }^{4}$

David: ...that idea of the armbands became stronger. By the first Milpirri we had them. Once that happened, and the kids were all wearing them, it sort of filtered through, gradually. The women, I think, came on next. They were down there going, quite proudly, 'Well, I am green group,' sort of thing ... that's a big experiment for a culture to actually go into itself and to then pull out unspoken things that are just supposedly known or learnt by being in it, and then going back and saying, 'No, we 


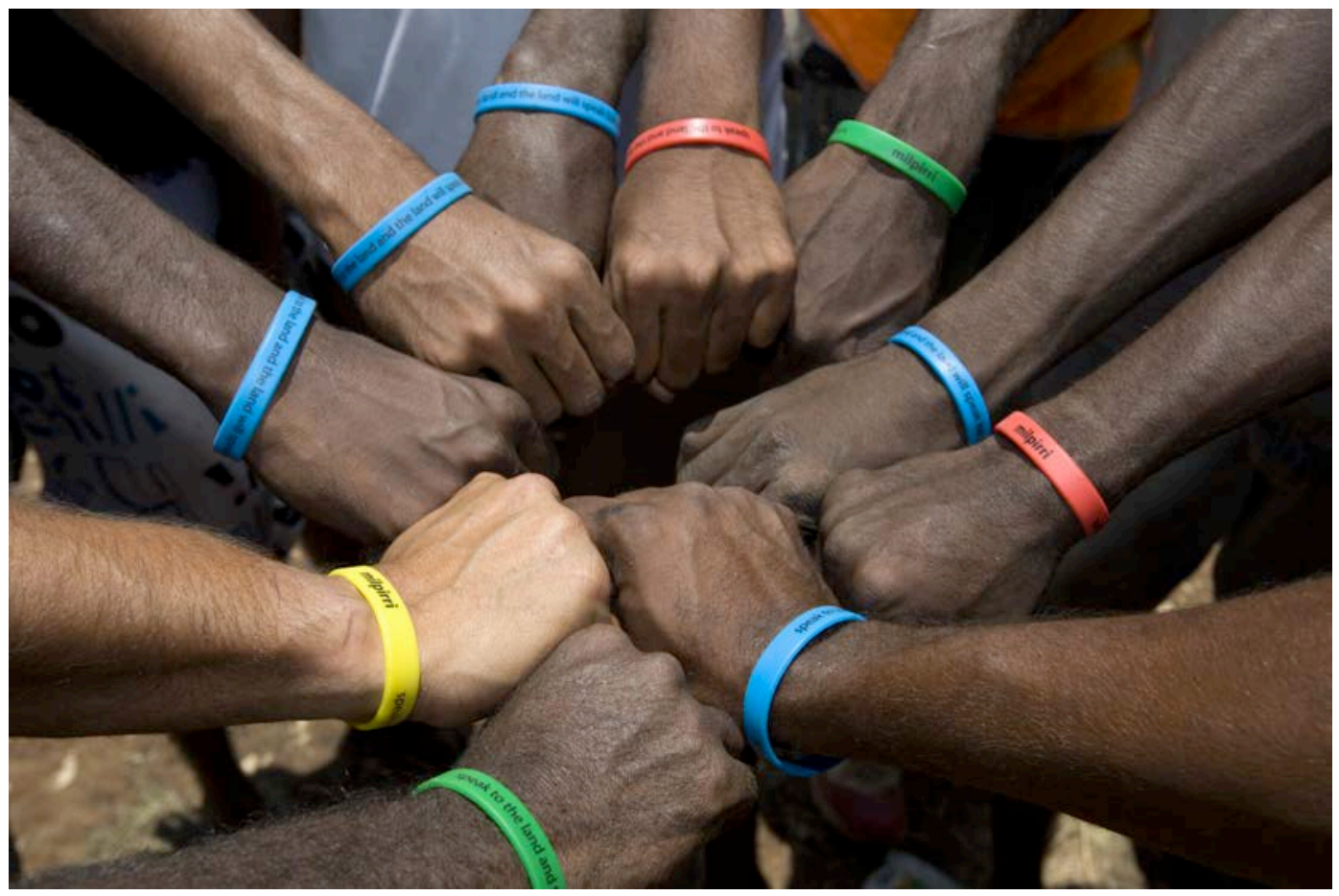

Image 4: Armbands, Milpirri Festival 2012, Lajamanu, NT (photograph: P. Eve; image ( Tracks Dance Company 2012)

are going to learn this now, or we are going to use this'. It works, because the people go 'Oh yes, I knew that' - without actually knowing it-so they bring it out into the open and therefore not only do they affirm it in themselves but outsiders look at it and they see the affirmation.

Tim: It is totally that 'seen and unseen thing'. ${ }^{5}$ You know, it is a thing that is totally there, and it is so important to that community, but it just wasn't seen. It just wasn't being seen by the kids, it wasn't being seen by the other non-Yapa ${ }^{6}$ people that were in that community - and then all of a sudden it was seen, and that armband...

Jennifer: Creating a presence...

David: It was ownership of the culture there, and also saying, 'I don't have to own it all, I own my piece of it.' Which is a much more ... not Warlpiri ... but a much more Indigenous way of thinking, instead of Westerners saying, 'You can own it all', or 'You should learn it all', or, 'You should have it all', (it says) 'this is your part and you look after it really well'. And they did. They took to that. 


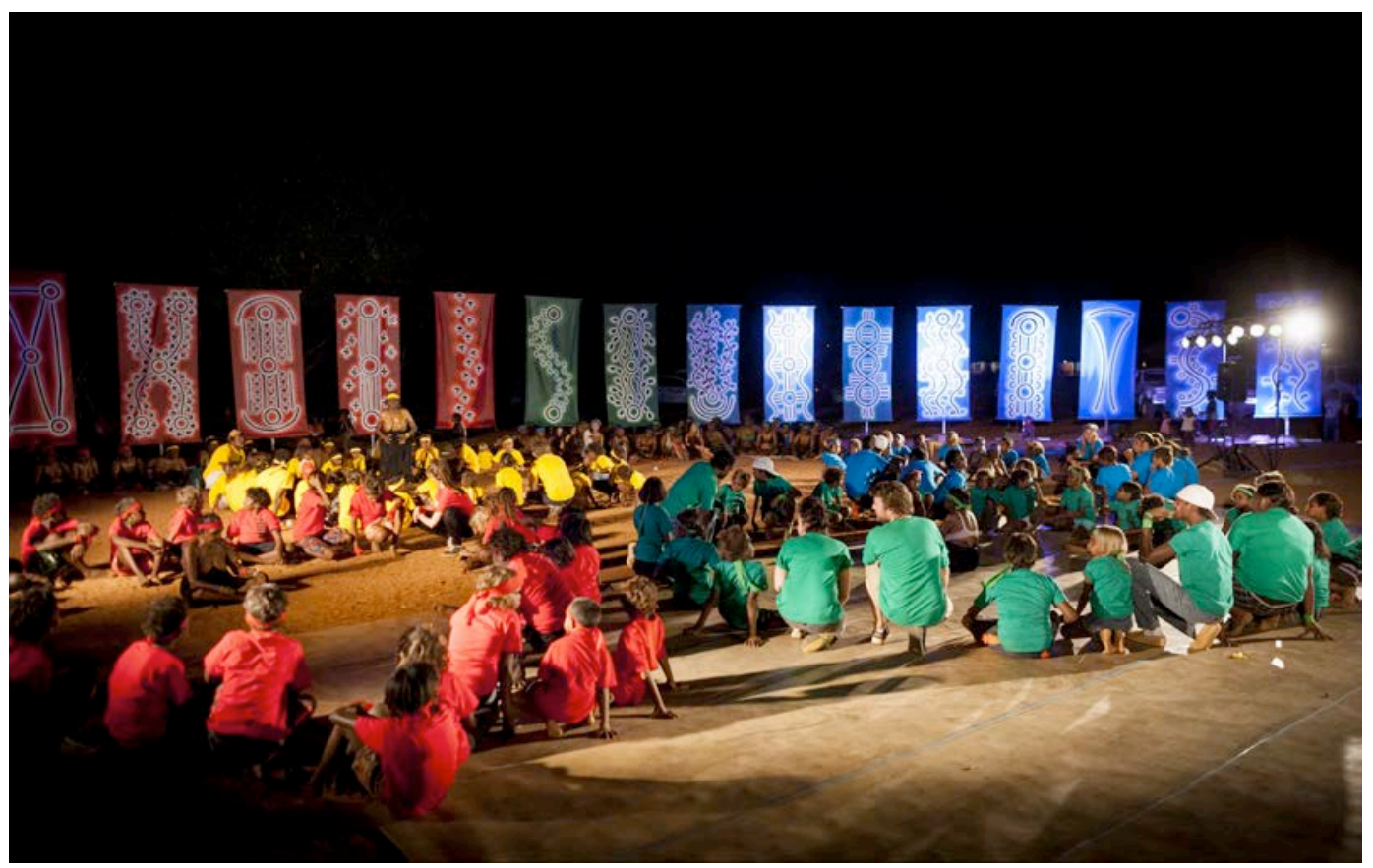

Image 5: Dancers and banners, Milpirri Festival 2012, Lajamanu, NT (photograph: P. Eve; image () Tracks Dance Company 2012)

Tim: And that other thing that happened with the colours, in the first Milpirri, was the idea of the banners which acted as a kind of backdrop for the Milpirri performers ... we've talked a lot about the concept of family coat of arms, that belong to the blue group or the red group and to start choosing these Jukurrpa designs that kind of represented the coat of arms for families, and these became banners which became the backdrop in these colours-and there were sixteen produced in the first Milpirri.

David: And they saw those banners on the scale of a sand painting as well. They weren't just little dot dots but they were something else ... you know, in the end, you go, there it is like playing cards almost. Here is a set of cards. Here is a set of images that goes, here's Lajamanu. ${ }^{7}$ And they love it. They identify really strongly with it in a way that's different to just someone sitting there doing dot-dot in their own painting, that's their personal thing, but the whole community can look and gobecause it's powerful. It's big. It's owned by the community. No one person can own it.

Jennifer: Well, could we just talk a little bit about that ... can you guys say something about-two things, I guess: one is, how you get funding for what is in fact a very 
specific community-based event without it touring, without it going national? Second, how you make the argument for-on top of that, if that weren't bad enough-it's ephemeral. It's going to disappear. It is like a one year, once a year thing on one day, one night, which weeks and weeks and months and months go into preparing-and it is gone. Which of course, I think is also hugely important.

Tim: We are about creating a work that celebrates place and people, and it is not important for that work to tour ... and I think that runs side by side with this Milpirri concept. I think we were very clear about knowing the things that come from developing performance with people that's about the place that they come from, which is ...

Jennifer: Site specific.

Tim: Yes. And the wellbeing that comes from celebrating who you are and where you live, and to look deeper into what is, what's there to celebrate about who I am and where I come from?

David: And we have got a benefit being up here in the Northern Territory that we are a long way away from decision makers ... which includes money-givers and gatekeepers to those things, and we've had to make up our own rules about what we do, and so we, in the Territory, look strongly to Indigenous practice but also to South East Asian practice, and both of those practices are really, really good at creating ceremonial performance or visual representations of themselves and place. And so most Western arts practice which is much more often about esoteric head space ideas and that could actually happen anywhere in world, because everyone can understand it ... Milpirri isn't about that at all. So getting it funded, in the same way as Western practice changes every few minutes, as to how you get ... You know, initially we were funded as a community cultural development program, we've been funded through Hybrid and New Media Arts, we've been funded through theatre, we've been funded through Aboriginal arts, we eventually reached a point where we were, to get ongoing funding in a three-year plan, we had to determine what we formally were, so we became a dance company.

Jennifer: So nowhere is as near as flexible as in fact Milpirri is, or nowhere in the funding world? Right? 


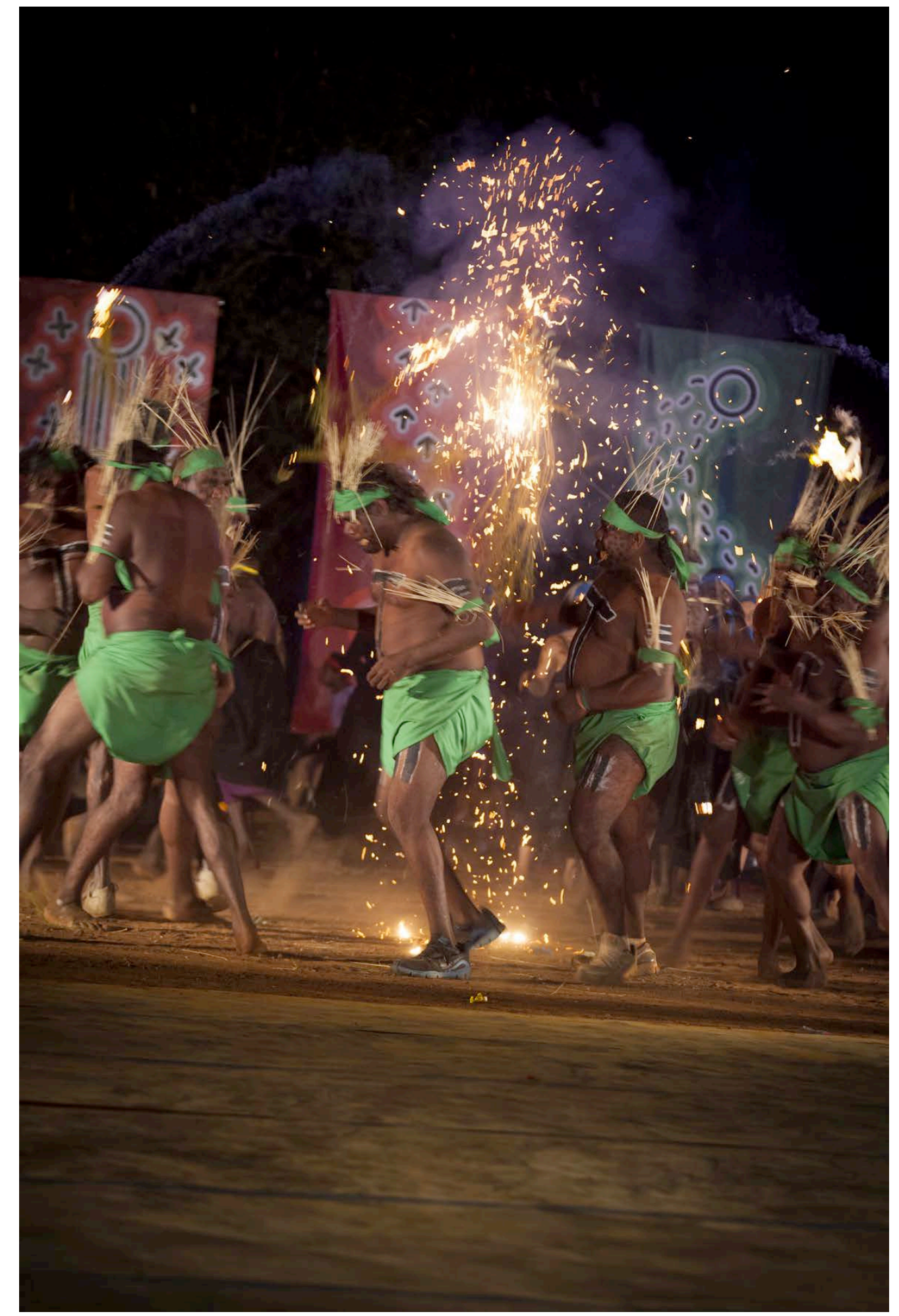

Image 6: Dancers, Milpirri Festival 2012, Lajamanu, NT (photo: P. Eve; image @ Tracks Dance Company 2012) 
David: The first Milpirri we got funded through the Myer Foundation-and in order to do that we had to win a Myer Award first, to put ourselves on the map, because we tried and they said, 'No one knows who you are.' From there we were able to go to the Rio Tinto Aboriginal Fund and got three-year funding for Milpirri. It also gets funding through Granites Mines Affected Areas money. It gets funded through-we were supported through the school, initially. The Lajamanu Progress Association, that the shop funds, and that pays the traditional performers, directly from their community, straight back to them. We're currently getting funding from Newmont Mines, which is the main mine that Lajamanu gets its royalties from. Yes, so the funding-every time-is a major issue, as to how we get that supported. The Australia Council generally funds the development of contemporary art-and a lot of stuff done in communities is seen as traditional. And so, Tim and I, then, having these arguments with the funding bodies, went and said, 'Ok, well, give us a research grant to research the contemporary notion of traditional-what you're calling traditional.'

Tim: ... we had people from the Australia Council coming up here going, 'Well, when are you going to do your professional development and when are you off to New York?' And we said, 'We want to go to Lajamanu!' You get more development there ... and at that point they were going, 'Well, you can't do that. That's the traditional artists. You know? We are supporting contemporary dance-making here' ... so we had to do a lot of arguing and battling.

David: And we, very strongly, have created a style of work, or processes, that are closer, in many ways, to a ceremonial approach. We are looking at the people, the place those people are from, the interaction of those people with that place, and that that interaction is often engendered-as you were saying-by ephemeral stuff. It's the day-to-day living, and it's the celebration of things that you do. It's having a meal together, and the meal's gone. It's about these. And so developing work that captures that ... but we also match that with trying to find concrete things that remain ... so we make sure its filmed and turned into a DVD that's of a quality that they feel proud of, and that they can show around. So we sort of play that field between what's ephemeral and what's concrete. It's a fine balance because people do need concrete evidence. 
Jennifer: How do you think your involvement in, and with, the experiment that is Milpirri has affected your purposes as creative directors?

Tim: I guess, over the last years, we've been trying to articulate the point of difference of Tracks to other dance companies. And a lot of people said it is actually our process that's very different. One of the first things going to Lajamanu, as a young person, you know, I thought I knew who I was as an Australian, what that meant. But to be growing up in country Victoria, to have no contact with Indigenous people and then to find yourself in Lajamanu, which is incredibly remote, and surrounded by people that are a different colour to me, speaking in a different language, who are Australian, for me, that just totally opened up that question ... you felt like you had to take off your shoes and throw them away and you had to sit out by the campfire and you had to sleep somewhere that you felt incredibly uncomfortable and you had to stop brushing your teeth, and you know I think you had the same experience.

Jennifer: You had to get head lice.

Tim: You had to get head lice and boils! And what is the interesting journey, is you don't learn how to be Australian by going, 'Oh, I am going to go all Warlpiri.' The question actually has to be asked of myself, where does my culture come from, how do I build a layer upon that?' And ... a key thing that drives me as an artist, is about asking that question about what does it mean to be an Australian, and I think this thing about being local and creating work that goes deeper into, what does it mean to be somewhere right here right now, has enormous relevance to the rest of the country. That's the question. Who are we?

David: I came up to Darwin to work and one of the first jobs I really had, and was working with Warlpiri mob, and some of the first things they said to me was, 'You've got no culture', 'Where's your country?' or, 'You've got no right to tell me anything.' It really did challenge me, and I had to think about how would I define my culture, when theirs was so clear to me? But this place-specific thing about becoming more connected to what that place is, that only comes from staying around ... and learning more and more about it. So for us, that is something as working artists that I very strongly learnt from Lajamanu and carry with me, is that, as an Australian artist, I am no good if I am just doing the biggest, broadest thing that anyone could do any- 


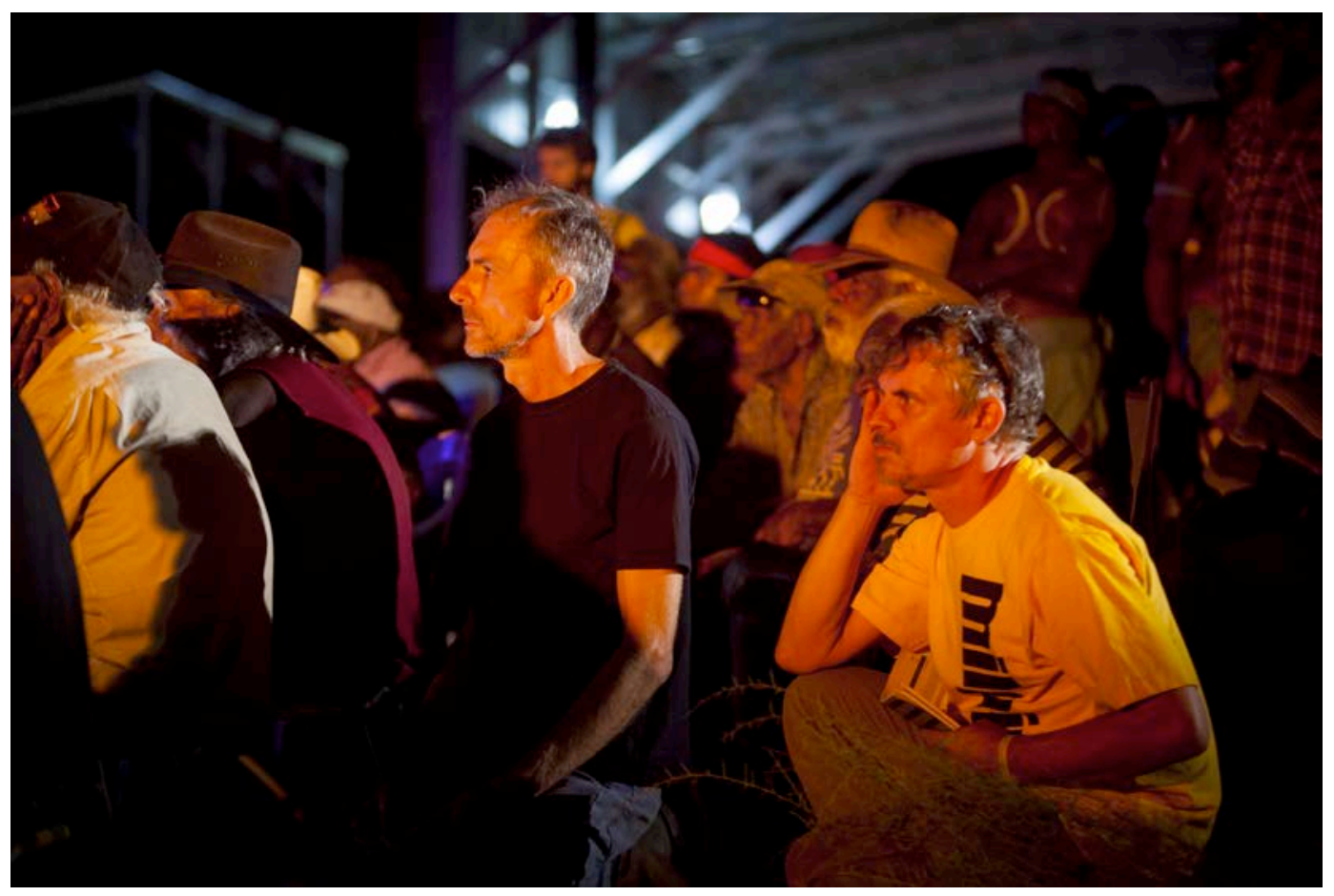

Image 7: Tim (Jampijinpa) Newth and David (Japaljarri) McMicken, Milpirri Festival 2012, Lajamanu, NT (photograph: P. Eve; image @ C Tracks Dance Company 2012)

where. The more local, the more specific, the more place-oriented I become in my work, the more Australian I feel. We love working in Warlpiri-it's like-you don't do ceremony all the time, you know, and then you come together, and that's when you do it. And then go off and you do your own, and then you come together, and that's very Milpirri, you know, once it's rained and there's grass and there's a lot of food, that's when we are doing ceremony. That's the celebration time. That's the important time. And so it's the same, expanded out, into the bigger picture, that you feel it's about coming together, and deepening that relationship, rather than having a new relationship each time. It's about that continuity.

Tim: And that's really what's interesting about that. The level of confidence in who you are and what you do, and the ability to be able to build on that, when you actually get a group of people together with a sense of confidence in each other. Not in an un-trusted relationship to go, 'Oh, this person is going to disappear after two weeks.' 
David: And they don't think what they are doing of as being innovative, experimental, contemporary, and yet it really is. It's really confronting and transformative, you know, like anyone that I talk with outside of that work, around Australia, in the arts, see it as amazingly transformative. 'You've changed the whole way I see myself as a person living here, you know,' and I'm going, 'That's what these people are doing,' and they are not doing it through ... hit and miss.

Tim: If we keep on track, we know it has an effect. You see it in their performance. When they go into this virtual world, almost, and we are spending lots on technology for Westerners to try have the same effect in their artwork, and these people just in an instant start one note and then they are into it. Then that's amazing, and I just find there's so much there, how it affects my art practice is, yes, the most affecting ... and I don't want to go to New York to do that. There's still too much down there.

David: I do feel the same.

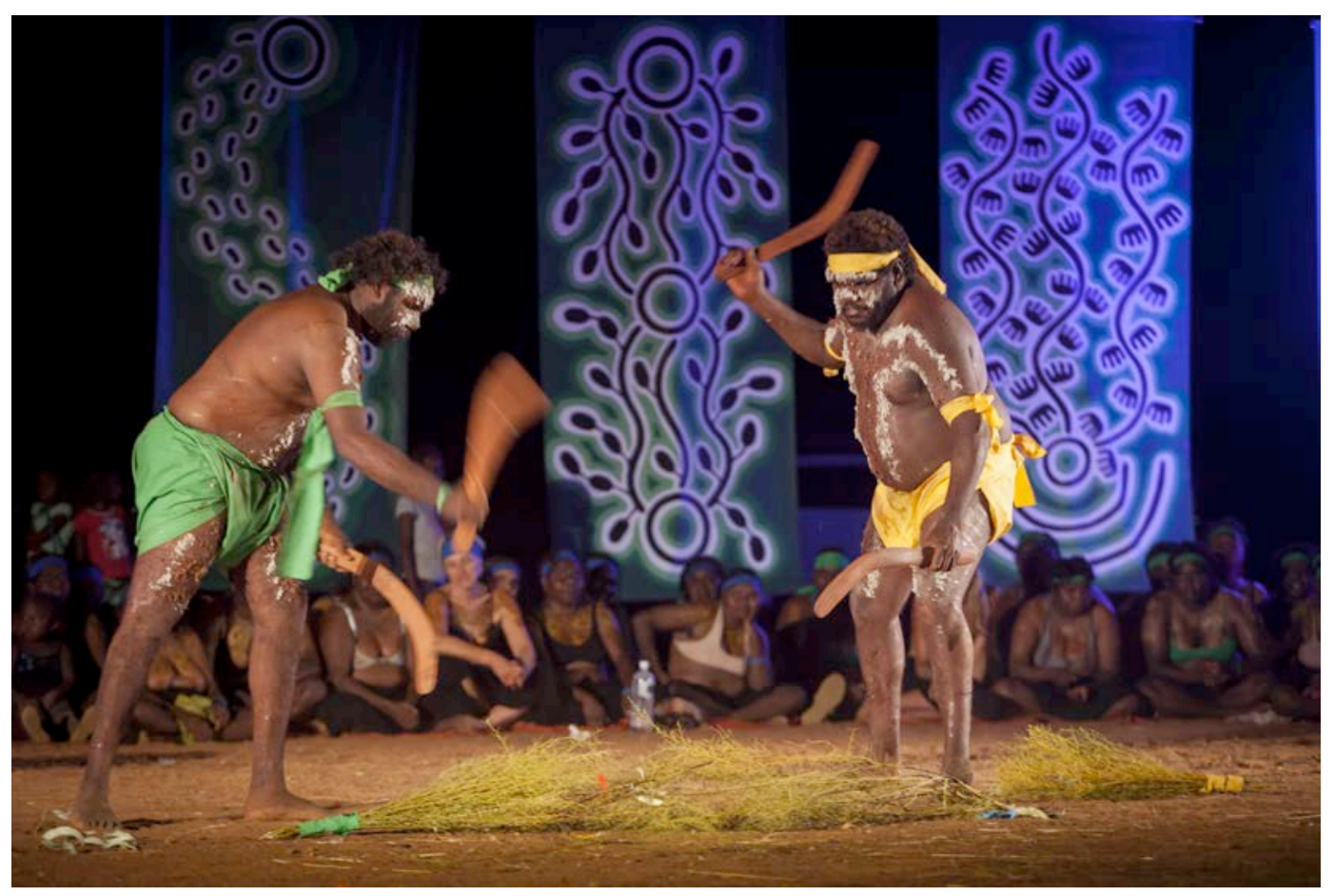

Dancers, Milpirri Festival 2012, Lajamanu, NT (photograph: P. Eve; image @ Tracks Dance Company 2012) 
David McMicken (AM) trained in education, dance, theatre, literature and music and has been a performer, director and founder of several companies along the way. He has lived and worked in the Northern Territory since 1991.

Tim Newth (AM) trained as a visual artist and is now a director of dance, theatre, and community arts. Based in Darwin since 1988, he creates spectacular outdoor performances that connect diverse people, place and culture.

Together, Tim and David are co-artistic directors of Tracks Dance Company. Since 1988 they have created over one hundred and twenty projects with community, forty-five with Warlpiri of Lajamanu, ranging from community residencies and performances, tours, exchanges in Darwin, Sydney, Melbourne and Wangaratta, and participation in Tracks Dance Darwin Festival seasons. Since 2005 Tim and David have collaborated with director Wanta Steve Jampijinpa Patrick on Milpirri.

\footnotetext{
-EDITORS' NOTES

1 The Garma Festival < http://www.garmafestival.com.au > is a leading intercultural festival event held annually in Arnhem Land. Wanta Steve Jampijinpa Patrick discusses Garma further in his article Pulyaranyi: Winds of Change, in this volume.

2 In 1996 Tracks, with senior Warlpiri artists and community members including Steve, travelled to country for which Steve is a traditional owner but to which he had not been before, on a research trip relating to Ngapa Jukurrpa (water or rain Dreaming)—specifically, to Kulpurlurnu, an important Ngapa Jukurrpa site. This trip became the basis of Tracks/Lajamanu production NGAPA

<http://tracksdance.com.au/ngapa-two-cultures-one-country> in 1997, as well as sowing the seeds for Milpirri.

3 Wanta Steve Jampijinpa Patrick worked for many years at the Lajamanu School as a bilingual teacher before becoming creative director of Milpirri (2005) and ARC Indigenous Discovery Research Fellow at ANU (2011).

4 Tim is here discussing how the skin groups or moiety divisions place each and every Warlpiri in relation to all other Warlpiri, as skin names are a shorthand for kinship terms. Literalising these relationships in colour groupings, as Milpirri has by developing wristbands and T-shirts in skin-group colour-as well as in the Milpirri Jukurrpa-skin group banners that form the backlit theatrics of the annual Milpirri stage-has created a way to visualise these relationships in new ways, both materially and physically. In Milpirri the children, specifically, use colour so they know where to dance in their appropriate skin/kin groups.
} 
5 Tim is referring to Wanta Steve Jampijinpa Patrick's description of Milpirri: 'it was an unseen thing, now it is a seen thing', discussed further in the editors' introduction, to this 'Same but Different' section in this issue of Cultural Studies Review. See also, Wanta Jampijinpa Kurlpurlurnu (Wanta Steve Jampijinpa Patrick), Miles Holmes and (Lance) Alan Box, Ngurra-kurlu: A Way of Working with Warlpiri People; Report 41, The Desert Knowledge Cooperative Research Centre, Alice Springs, 2008.

6 The term non-Yapa here refers to white people, or Kardiya.

7 The figure of playing cards here is used to elucidate Warlpiri kinship or moiety divisions. Both a standard deck of cards and Warlpiri moiety divisions are in a group of four sets or suits that are fixed, not determined by the individual, and stand in determinative relationship to other members.

\section{-BIBLIOGRAPHY}

Kurlpurlurnu, Wanta Jampijinpa (Patrick, W.S.J.), M. Holmes and (L.)A. Box, Ngurra-kurlu: A Way of Working with Warlpiri People; Report 41, The Desert Knowledge Cooperative Research Centre Alice Springs, 2008. 